THIRD GENERATION COMPUTER USED TO CONTROL FUEL ELEMENT ASSEMBLY

G. E. Cort and R. J. Agosti

March 1969

Westinghouse Electric Corporation

Astronuclear Laboratory

Pittsburgh, Pennsylvania 


\section{DISCLAIMER}

This report was prepared as an account of work sponsored by an agency of the United States Government. Neither the United States Government nor any agency Thereof, nor any of their employees, makes any warranty, express or implied, or assumes any legal liability or responsibility for the accuracy, completeness, or usefulness of any information, apparatus, product, or process disclosed, or represents that its use would not infringe privately owned rights. Reference herein to any specific commercial product, process, or service by trade name, trademark, manufacturer, or otherwise does not necessarily constitute or imply its endorsement, recommendation, or favoring by the United States Government or any agency thereof. The views and opinions of authors expressed herein do not necessarily state or reflect those of the United States Government or any agency thereof. 


\section{DISCLAIMER}

Portions of this document may be illegible in electronic image products. Images are produced from the best available original document. 


\title{
THIRD GENERATION COMPUTER USED TO CONTROL FUEL ELEMENT ASSEMBLY
}

\begin{abstract}
This paper presents an example of the use of third generation computers to control the assembly of fuel elements in a nuclear reactor. Through a combination of engineering calculations and a business type data handling system to provide checking and quality control monitoring, an individual set of assembly instructions is produced for each unique fuel element. The result is an optimized thermal performance for each solid graphite enriched uranium fuel element which operates within narrow limits of the average core temperature. Many fuel elements with up to a hundred different detail drawing configurations are used in each reactor. Approximately fifty different input quantities are needed to dosr $u^{*}$ tach el nment. These data are stored on four different magnetic tapes with public READ access, but WRITE access restricted to four different functional groups responsible for processing and updating the information on its own tape. The program uses these four controlled access tapes as input for the engineering calculations, for verifying that all elements were properly inspected and released, and for monitoring the assembled reactor against the planned design configuration.
\end{abstract}

\section{DESCRIPTION OF REACTOR}

The active core of the NERVA nuclear reactor consists of solid graphite enriched uranium fuel elements, each containing many individual flow channels. Many fuel elements are clustered together to form the cylindrical active core volume. Hydrogen propellant is heated in these axial flow channels from cryogenic temperatures at the inlet to well over $4000^{\circ} \mathrm{R}$ at the exit. To protect the graphite from chemical attack by the hot flowing hydrogen, the channels are coated in a vapor deposition process with refractory metal carbides. Orifice flow meters are installed at the inlet end of the fuel elements and are sized according to the expected heat input and hydraulic diameter. The significance of precise temperature control can be appreciated by considering that the engine's performance increases rapidly with the average propellant exit temperature while the graphite corrosion rate increases exponentially with temperature.

\section{PROGRAM PURPOSE AND LIMITATIONS}

To build the reactor rapidly, installing the correct size orifice meters in the correct element and assembling the element into the correct cluster without error requires excellent communication between engineering and reactor assembly personnel. The orifice meter sizes are calculated by the computer program under discussion and results are displayed in a compact, readable instruction printout used directly to assemble the core. Over fifty separate pieces of information are needed as input to describe each fuel element and its core location. One use of these data is to calculate the required orifice meter sizes for a 
uniform exit gas temperature from each element. The instruction printout not only specifies these orifice meters, but also assigns the fuel element to its unique core location. The computer checks the fuel element characteristics such as uranium loading and hudraulic diameter to assure they are within specification tolerances. In addition, it verifies that the fuel element was properly inspected and the assigned reactor core location is consistent with its detail drawing identification.

Figure 1 is a sample printout of these assembly instructions for a part of one cluster. Two fuel elements are on the page with the required orifice sizes designated. The data blocks along the right-hand margin are to be filled in by the technicians and/or inspectors as a check that assembly operations are completed. Note that the orifice meters are colorcoded by the use of a plastic cap and photos are taken as a permanent record. The identifying five digit element seria! number printed on Figure 1 is engraved on the graphite fuet element at the earliest practical stage of production. The four character core location code, printed beside the serial number, assigns the fuel element to its unique core location and standard orientation. This printout, which carire; the status of a drawing, is used as primary assembly instructions by the reactor assembly technicians to build the active core volume from the inventory of fuel elements. Other assembly drawings are, of course, required for building the clusters, and for assembling the clusters into the completed core. The designation of unfueled, instrumented elements and nuclear shimming requirements is also carried on this printout.

The orifice meter calculations and the quality control checking are carried out in one job submittal, so that reactor assembly can proceed without delay. To complete the core, numerous computer runs over a time interval of weeks are necessary to accommodate new production, replace elements damaged in shipping and handling, and adjust reactivity shimming. The magnitude of the quality control function is illustrated by the fact that many fuel elements with up to a hundred different detail drawing identifications are produced per core. Each element is inspected many times during production and assembly for conformance to close external dimensional tolerances, thickness and corrosion resistance of carbide coating, uranium content, hydraulic channel diameter, etc. Because of the high reliability requirements common to aerospace projects and vulnerability of the graphite fuel elements to damage, rejection rates are relatively high. This places even greater importance on the quality control monitoring feature of this computer program.

Although the program has been specifically designed for the NERVA reactors, it is versatile enough to be used with any solid core reactor built up to discrete fuel elements containing parallel flow channels. It probably could be adapted to a liquid-cooled parallel rod bundle core as well. Its primary utility is in cases where a large amount of basic nuclear power prediction and fuel inspection data must be quickly brought together to define a set of optimized assembly instructions for the reactor core.

\section{PROGRAM ORGANIZATION}

Four controlled access tapes under the third generation computer's permanent file manager system are used as the primary input to the program. Some of these tapes are also used in other phases of the operation, such as inventory and criticality control. Each tape is the responsibility of a different functional group within the laboratory. The responsible group has the only WRITE access to its tape (by specifying a series of four code words, for example). Users of the tapes have READ access only. The tapes, described in Figure 2, are updated as often as necessary by the responsible groups so that the latest information is 
NRX-A6 REACTOR, CONFIGURATION 123C, JPDATE 12, 4/25/67

CLUSTER 43

1. CORE LOCATION 0734 ORIFICE METER SIZE :

USE 3 , SIZE C , DIAMETER 0.145 INCHES, COLOR CODE BROWN

2. CORE LOCATION 0735

ELEMENT SERIAL NUMBER 64318

ORIFICE METER SIZE :

USE 1 , SIZE B , DIAMETER 0.175 INCHES, COLOR CODE YELLOW

CLUSTER 43 CONTINUED ON NEXT PAGE:

\section{CHECKLIST DATA BLOCKS}

ACCOUNTABILITY

OPERATOR

INSPECTOR

PHOTO TAKEN

PHOTO VERIFIED

LEAK CHECK

VISUAL INSPECTION

ACCOUNTABILITY

OPERATOR

INSPECTOR

PHOTO TAKEN

PHOTO VERIFIED

LEAK CHECK

VISUAL INSPECTION

Figure 1. Sample Assembly Instruction Printout 


\section{DESCRIPTION}

TAPE 1

ELEMENT INSPECTION

DATA

TAPE 2

NOMINAL CORE

NUCLEAR PARAMETERS
RESPONSIBILITY

(WRITE ACCESS)

THERMAL AND HYDRAULIC

ENGINEERING GROUP

(USING INFORMATION

SUPPLIERS)

NUCLEAR ENGINEERING

GROUP
FURNISHED BY FUEL
DATA

ELEMENTS LISTED BY

SERIAL NUMBER WITH

ASSIGNED CORE

LOCATION (IF ANY) AND

MEASURED PARAMETERS.

LIST OF ALL CORE LOCATIONS WITH NORMALIZED POWER DISTRIBUTIONS.
EXAMPLE

SERIAL NUMBER, URANIUM LOADING, HYDRAULIC DIAMETER, GRAPHITE

PERMEABILITY, DIMENSIONAL INFORMATION

PROCESS INFORMATION (MATERIALS USED, EXPERIMENTAL PROCESS, SUPPLIER, ETC.), ASSIGNED CORE LOCATION.

CORE LOCATION, LOCAL RADIAL POWER (NORMALIZED), NOMINAL URANIUM LOADING USED TO OBTAIN POWER

DISTRIBUTION, AXIAL POWER DISTRIBUTION

SERIAL NUMBER, DETAIL DRAWING IDENTIFICATION, DESCRIPTIVE INFORMATION.

FUL ELEMENTS WHICH MEET SPECIFICATIONS

TAPE 4

CORE CONFIGURATION ENGINEERING ADMINISTRATION GROUP
LIST OF ALL CORE LOCATIONS WITH REQUIRED

ELEMENT PART NUMBER
CORE LOCATION, REQUIRED DETAIL DRAWING IDENTIFICATION FOR FUEL ELEMENT TO BE USED IN THIS LOCATION, DESCRIPTIVE INFORMATION

Figure 2. Description of Primary Input Tapes 
aiways used for each job submittal. This is important for the NERVA application since new production elements are normally being fed into the system, while others may be deleted for damage in shipment or handling.

Tape 1, the responsibility of the thermal and hydraulic engineering group, consists of two binary coded decimal records per element. These tape records contain the element's unique seriol number, its assigned core location, and measured characteristics important for sizing orifice meters. The data for spare elements, containing blanks in the core location field, can also be stored on this tape. The fuel elements are assigned to core locations, by filling in the appropriate core location code in this field. Tape 2, the responsibility of the nuclear analysis group, consists of two binary coded decimal tape records for each core location, and includes a complete description of the nominal nuclear characteristics. Each fuel element location is described by the core location code, normalized nuclear power generated at that location, and the nominal uranium loading used to calculate the power distribution. This tape is prepared based on nuclear analysis and experiments carried out before the ctart of core assembly.

After sorting Tape 1 according to the core location code (see Figure 3 for the program sequence), the program matches these locations against corresponding locations on Tope 2. The program then checks input data for validity (such as the measured loading on Tope ! inc within bolerance of the nominal loading on Tape 2). It prints an error message if required, or if no errors are found, proceeds to the subroutine to calculate orifice meter sizes as indicated by Figure 3. To save computer time that would normally be consumed in tope handling, the information taken from the tapes is stored in memory. This requires the use of a $64 \mathrm{~K}$ memory plus storage of three variables simultaneously in one memory location by appropriate programming.

The parametric thermal and hydraulic reactor data, orifice meter characteristics, and control indicators for the orificing are read in from data cards. Required meter sizes are calculated after the measured uranium loading for the fuel element has been used to adjust the nominal local power prediction given on Tape 2. Based on the corrected local nuclear power, the element's measured hydraulic diameter and the parametric reactor data, the required orifice meter size is determined. The nearest available size is selected from the inventory of discrete sizes available and the as-built exit gas temperature is calculated for the selected size. The measured reactor exit gas temperatures from the most recent NERVA test exhibit very little random scatter due to the combination of uncertainties in nuclear power prediction and fuel element measurement, reactor design point prediction, and selection of orifice meter sizes.

The output from the orifice meter size calculations is the complete cluster definition shown in Figure 1 which goes directly to reactor assembly personnel. In addition, a printout of auxiliary engineering information including the element's power generation, flow rate and exit gas temperature is produced. Also, the assigned core locations and fuel element serial numbers are saved to monitor the assembled core. This list is designated "Tape 5" in Figure 3, but is normally on a disk file for immediate use.

After completing the assembly instruction printouts for the fuel clusters, the computer monitors the as-built core for quality control purposes. This checking option is a separate program, (designated "CHECK" in Figure 3) called by control cards using the internal file management system. It compares the list of serial numbers and core locations on "Tape 5" against the Certified Element List (Tape 3) and the Core Configuration (Tape 4) as described in Figure 2. Tape 3 is the responsibility of the quality control group whose 


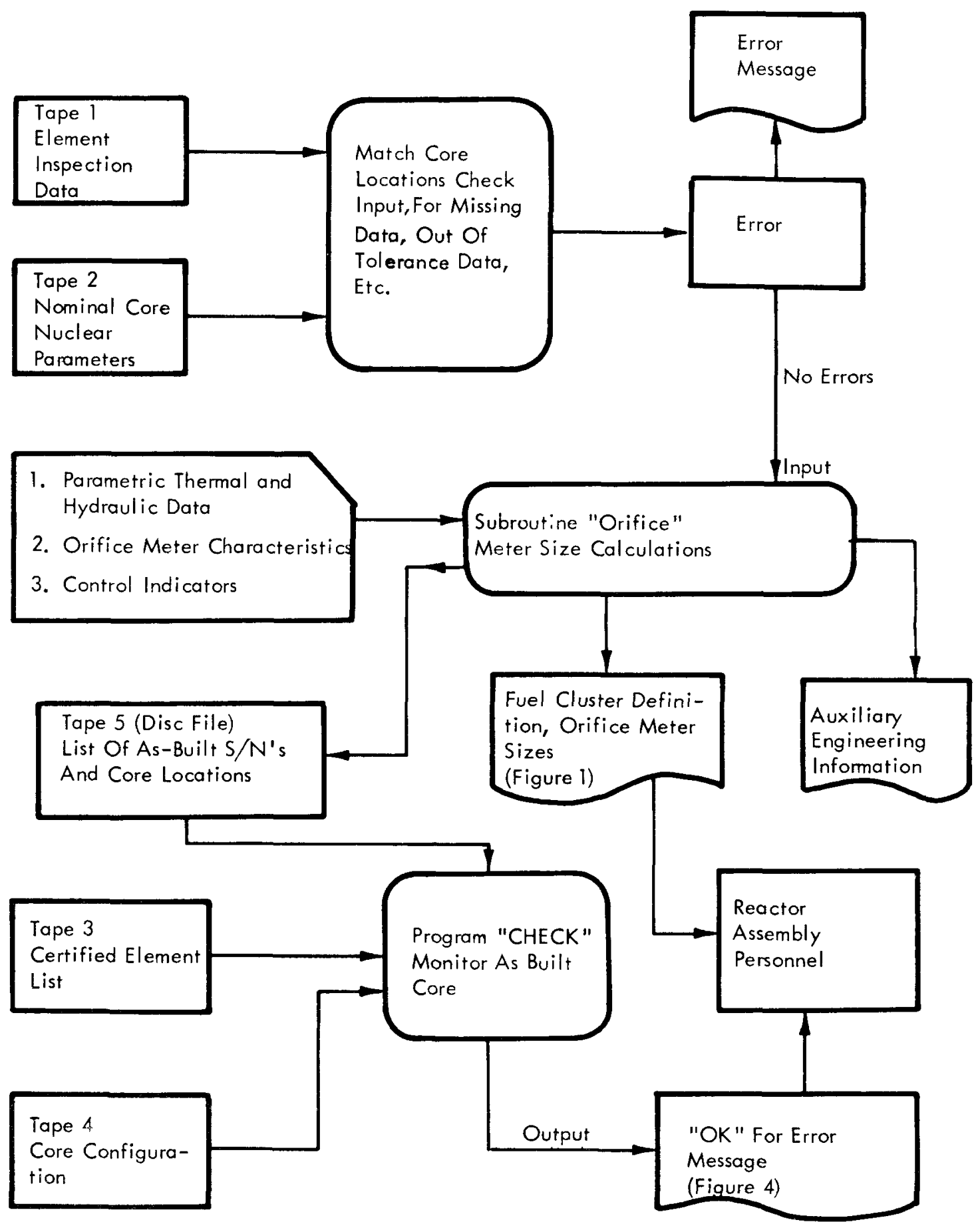

Figure 3. Program Sequence for Fuel Element Orificing and Assembly Code 
responsibility is to verify that the elements have successfully passed through the detailed inspection, non-destructive testing, and other certification procedures as required by drawings and specifications. There is one binary coded decimal tape record per element containing the serial number and part number (detail drawing identification) to which the element was inspected and released. Auxiliary descriptive information is provided on this tape to assist in inventory control.

Tape 4 is the responsibility of the engineering administrative group which controls the reactor drawings and the formal change order system. The required fuel element assembly configuration is stored on this tape with each record containing the reactor core location and the required element part number for that location. Changes to this tape are frequently made while the reactor is being put together and all changes are controlled by the responsible group with appropriate signatures to drawings, followed by a tape update. The identification of Tapes 3 and 4 remains constant for each reactor, so that users need only request the tapes using the appropriate code words to obtain the latest information. Each tape is identified by a title, latest update sequence, and calendar date as the first record. The printout of the check program contains these identifications plus the title and update information printed on the fuel cluster definition (Figure 1) furnished to the assembly personnel. The sample printout in Figure 4 includes a summary of the elements checked and iists any error messages. In this example, ten new elements were added to the core and ihree errors were found. The first error indicates the element assigned to location 0735 is not on the Certified Element List. This might occur, for example, because the element (serial number 64318) had been damaged and deleted from the most recent update revision of Tape 3. The second error shows that the required detail drawing identification for location 1403 given by the Core Configuration tape (Tape 4) does not agree with that of the actual element given by the List of Certified Elements (Tape 3). This could be caused, for example, by a keypunch error in preparing either tape. The third error, affecting core location 0042, is similar to the second. In this case, the part number letter revision has not been updated on Tape 3 from $L$ to $M$ as required by the core configuration tape (Tape 4). This might occur, for example, due to oversight, or it may be that the element, when re-inspected, did not meet the new drawing requirements. Typically, one would not expect this many errors in one run containing only ten elements. The errors would normally occur because of changes in the element's status on the quality control certified list (Tape 3) or, more rarely, changes in the desired core configuration. These changes are incorporated info Tapes 1 or 2 (which will define the as-built core) before the job is executed, and the checking program provides a back-up to guarantee that desired changes have been made.

After the errors indicated in Figure 4 have been corrected by assigning new elements in the as-built reactor, a re-run of the orifice calculations and checking option will produce a printout showing zero errors. It is then forwarded to the assembly personnel verifying that the new assembly instructions (Figure 1) have been checked and that the ten elements are to be orificed, clustered, and added to the reactor in the locations shown.

Rapid, error-free communication of the many thousands of reactor assembly details is vital to this phase of the NERVA reactor construction.

\section{ACKNOWLEDGEMENT}

The Nuclear Engine for Rocket Vehicle Application Program (NERVA) is administered by the Space Nuclear Propulsion Office, a joint office of the U. S. Atomic Energy Commission and the National Aeronautics and Space Administration. Aerojet-General 


\section{TAPE IDENTIFICATION}

TAPE 3 CERTIFIED ELEMENT LIST 471B233 REVISION $14.4 / 22 / 67$

TAPE 4 CORE CONFIGURATION NRX-A6 REVISION 3. 4/10/67

TAPE 5 AS-BUILT ELEMENT LIST 123 C UPDATE 12. 4/25/67

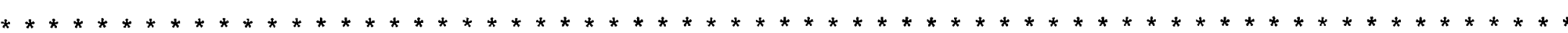

CHECK OPTION EXECUTED $4 / 25 / 67$

10 ELEMENTS ADDED TO AS-BUILT REACTOR

10 ELEMENTS CHECKED

3 ERRORS FOUND

ERROR SUMMARY FOLLOWS -

AS-BUILT CORE

SERIAL NUMBER

CORE LOCATION

64318

0735

82141

1403

0042

04302
CERTIFIED ELEMENT LIST

\section{CERTIFIED ELEMEN
TAPE 3}

PART NUMBER

$$
\text { MISSING }
$$

82141

04302

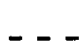

$104-M-110$

$721-L-453$
CORE CONFIGURATION

TAPE 4

0042

Figure 4. "CHECK" Option Sample Printout 
Corporation, as prime contractor for the engine system, and Westinghouse Electric Corporation, as subcontractor for the nuclear subsystem, are developing a nuclear propulsion system for space applications. 